\title{
Design of recreational corridor planning of Henan vernacular landscape based on resource integration
}

\author{
Xiaofei Zhang \\ Institute of art and design, Huanghe Science and Technology College, Zhengzhou, China, 450063 \\ zxfhhkj@163.com
}

\begin{abstract}
KEYWORDS: Riverside recreation corridor; Cultural route; Vernacular architecture art; Folk art ABSTRACT. The "livable village", "beautiful country" and "land ownership reform" and a series of related construction of country government work report, provide the policy basis for the local landscape protection, unique quality and value more and vernacular landscape more people pay attention to. The majority of rural Henan province geographical differences, face protection of vernacular architecture and folk art of the opportunities and challenges of each are not identical, combining with the Henan province rural landscape resources distribution characteristics and current situation of tourism planning, from the greenway planning point of view, to explore the way of integration of township planning building art and folk art.
\end{abstract}

\section{Introduction}

Greenway is a new planning form, as a concept first appeared in the United States Charles "greenway" a book. The original definition is used for recreation or ecological protection of non motorized trail system can be slow, along the river, ridge, valley, abandoned old course arrangement, plays a series of different nature attractions role. Greenway planning case is one of the earliest of the early nineteenth Century Olmsted for the Boston Park do green necklace, the initial motivation was to provide migration corridor for the ecological plaque of the communication between the animal and plant energy, because of its flexible form, has been widely used and the ecological security of network construction, cultural route opened, recreation facilities construction field.

\section{Henan vernacular landscape resources status}

Henan profound historical and cultural heritage, has the rich local landscape resources, but because of the difference of geographical environment and historical factors, the existing types of vernacular landscape resources in various regions, the distribution characteristics and the current situation of the protection of each are not identical, the western mountains, rich natural landscape resources in most areas are included in the set, the protection system of nature reserves, the world geological parks, National Geological Park, Forest Park, scenic spots planning surface shape. But the local cultural landscape resources is relatively single, mainly some ancient villages retain more complete, less quantity.

The eastern plains fertile soil, cultivation has a long history, local humanistic landscape resource type is various, but affected by the change of dynasties and the war of the larger, more serious destruction of rural landscape resources, the traditional settlement form complete rare landscape resources, shows fragmentation inclination. In addition, but because of the fertile soil, cultivation has a long history, affected agricultural production, natural landscape and biodiversity resources gradually degradation, strip the only surviving biodiversity resources is extruded on the riverside. Due to the lack of large-scale tourism benefits, in the east of Henan Province not only geological parks, nature reserve, Forest Park and other blind planar planning system, also with the ancient village, town and a kind of dot planning system without edge.

The natural landscape resources in hilly area of the Midwest is no mountain so visually attractive, but more suitable for agricultural production and living, human activity is a long history, rich cultural landscape resources, and cultural landscape heritage remained relatively complete, ancient villages, ancient town most distribution in the mountains to the plains of the transition zone, however, these ancient village, town in the cultural relics protection system to the point of the morphology of dispersed exists, it is difficult to form the integrated tourism benefit and social 
benefit, so, looking for the planning of a more reasonable way, vernacular landscape conformity resources, into the tourism system is an effective protection strategy.

\section{Based on the local landscape resources protection corridor planning strategy}

The construction of riparian ecological corridor, linking local humanities landscape point cloud. Corridor of landscape and tourism of Greenway interpretation in the planning system of the western countries is the non motor vehicle slow trail tourism system, mainly composed of pedestrian, bicycle lanes and other non motorized trails and parking, boat docks, car rental shop, rest stops, tourist shops, specialty shops and other recreational facilities and a certain the width of the green buffer zone. Along the riverside, such as valley, ridge line along the natural corridor, or is used as a recreational activities such as disused railway lines, ditches, scenic roads and other artificial corridors established linear open space, including natural landscape all lines for pedestrians and cyclists to enter and artificial landscape line. It is connected to the park, nature reserve, scenic spots, historical sites, and other with high density gathering areas of open space link. Green road construction is not intended to replace the traditional scenic area of plaque and plaque, it is complementary to the scenic spots. The existence of the ecological benefits of green road to make original scenic area to play and to achieve, and compared with the area of plaque traditional tourist spots, it has ecological significance of higher, promote the effective circulation of internal landscape ecological system, and strengthen the close connection between the plaque, continuity, to maintain habitat and habitat network main chain the integrity and effectiveness of the.

The middle east plain area of Henan province rural landscape resources are mainly dispersed in the countryside of the secondary units of cultural relics protection and riparian forest as well as by the historical and cultural celebrities, social customs derived non material cultural landscape. There are units of cultural relics protection in construction sketch form, quantity, type, form more rich and colorful, lively and vivid, with a very high artistic value and archaeological value, but the layout is scattered, small scale, like a number of scattered point cloud, the lack of continuity of the landscape, high cost of travel, because cannot be incorporated into the system of tourism planning in concrete, the the economic value of social benefit has not been brought into full play. With reference to Europe and the United States Green Road Planning and the planning of heritage corridor of the successful experience, linear programming has a form and motor selection more flexible space, to become the best choice.

Rural landscape corridor planning, first select the continuous enhancement of landscape elements, landscape connectivity and degree of polymerization. The continuity of the landscape elements in Yudong plain area, mainly for the rural road and riverside embankment lined with two factors, rural road along the historic and cultural landscape retained less, recreation corridor construction relying on highway plays the role of aggregation of vernacular landscape. Secondly, the important function of rural highway to undertake urban and rural logistics, passenger transport, relying on the scenic corridor construction of modern highway systems will increase the burden of highway transportation. On the contrary, relying on natural rivers open landscape corridor, it has a lot of advantages. The river is the source of life, the earliest human civilization are concentrated in the coastal rivers, historical and cultural landscape heritage accumulated more, at the same time the inland shipping function has now been completely be replaced by highway traffic, no modern industry production, gluttony consumption the destruction and pollution, also make the riparian areas become native Heritage Landscape in good preservation, distribution the relative concentration of the region. Relying on the Riverside Avenue building rural greenway, can be connected in series on point cloud more local humanistic landscape. In addition, the river is the natural ecological corridor, on both sides of the river ecological foundation is better, wild animal and plant resources relatively abundant, riparian greenways can integrate the country historical culture and ecological two landscape resources, the cultural heritage of rural landscape resources scattered together.

According to the status of Henan province and the human condition, Huaihe two tributaries, covering the middle east part of Henan plain area, such as the Sui River, Tuo River, river vortex, Ying River, Honghe River was "chandelier", "palm shaped" balanced distribution of Huang Huai plain hinterland, these rivers flow stability, riparian ecological environment development is good, the bank line of twists and turns, cross-strait villages have dense, green road construction conditions, 
construction of the greenway series, easy adhesion more rural landscape cloud point, to line net, to the fixed network point, take the role. Green road construction is not only the rural recreational facilities, but also the ecological infrastructure construction. Not only can unite local cultural landscape resources, also can strengthen and cultivate the rural ecological landscape.

Build cultural line, series traditional settlements. In the natural landscape of Henan mountain in the western and the eastern plain in the Middle Hilly areas although unlike mountain so magnificent, but more suitable for early human habitation and agriculture production, so, the foothills humanities landscape resources is abundant, many historical and cultural celebrities were born here, such as Han Yu, Du Fu, Liu Yuxi, Du Mu, Li Shangyin, Sima Guang, Cheng Hao, Cheng $\mathrm{Yi}$, there is a lot of historical and cultural celebrities of the historical sites and cultural legends, they constitute a native heritage cultural attractions village, these legends to create a poetic atmosphere of native landscape.

Due to geopolitical advantage, hilly area with a corridor and edge effect in ecology, plant community dynamic exchange not only energy channels, often also ancient economic and cultural corridor and military fortress, many road site, and Guan Ai distribution in this kind of environment, such as the famous ancient road in Western Henan North Road, Nan Xiao letter Xiao letter road, Wan Luo Road, and the road related and some ancient transportation facilities, such as post, bridge, Guan Ai, Inn and port, such as Gan Tangyi, di Hua Yi, Qing Yun Yi, general of the Taihang pass, Zi Xia, Guan, tianjingguan, these road along the landscape resources destroyed small dynasties change and war, retained the morphology was more complete, and relying on the valley area of distribution, strong continuity, through cultural lines and customs corridors and other linear programming model to facilitate more integration of tourism resources.

Vernacular architecture in hilly area of western Henan has distinct local characteristics, and has the characteristics of relatively stable. The publication of the national housing construction department and bureau of cultural relics of the ancient village in the three batch, 99 ancient villages in Henan, more than $90 \%$ of them distributed in Hilly area. The local stone art, brick and tile technology, brick art, wood carving art well preserved here, some settlements, the mountain on the potential, lapel hill water, presents the architecture and environment highly fit form. Such as Xiao letter Road on the Shanxian underground Kiln Park, Mianchi Zhao Gou tou Cun, Lingbao, Yang Gong Zhai, Mengjin Qiao Zhuang Cun, Nan Xiao letter Road on Luoning County on the Ge Cun, etc.. Due to the relatively closed nature of social environment, the regional social atmosphere is relatively stable, the village folk and folk art with distinctive local characteristics, a kind of landscape resource reservation is also more complete and rich, such as the Dabie Mountain and hilly area of Flower Drum Opera, Funiu Mountain hilly zone Shehuo, Daoqing etc.. These customs and folk art form living factor of vernacular landscape, vernacular landscape more social attributes gives.

In addition, hilly area in the west of Henan Agricultural Technology and production level obviously is higher than the mountain, but because the plots not plain area is flat, fertile soil of no use in Yudong plain area, agricultural production in a variety of operating mode, characteristic planting industry is the regional rural landscape advantage industry, such as the tea industry, medicinal plant, fruit industry, breeding characteristics, and traditional handicraft industry derived from the first industry, such as paper, silk, brewing, bamboo weaving, ceramics and so on, these are the characteristics of agricultural production chain on a rural landscape. These industrial landscape reflect specific under the restriction of environment, sustainable land use suitability concept and technology, but also reflected the characteristics of the rural landscape unique geographical environment of the agricultural production system, which reflects the harmonious relationship between man and land, provide a variety of products and services for the local residents.

Constitute the two major advantages of rural landscape of the geographical environment in the rich historical and cultural heritage landscape resources and industry characteristics of landscape resources. Woven pluralistic culture tourism network through the cultural route of carding, series of local history cultural heritage attractions, run on the characteristic industry of landscape patches. In addition, these areas are often still retain the rich and colorful folk culture resources, the mining of these folk cultural landscape arrangement, can create a better atmosphere of rural landscape. 


\section{Summary}

From the rural landscape resources distribution features, riparian ecological corridor construction and cultural route of exploring the existence of great advantage in investment cost, accessibility, many cultural attractions are scattered on the river and the valley sides, even far away are not more than $30 \mathrm{~km}, 80 \%$ in the $10 \mathrm{~km}$ range. Riparian ecological corridor planning and cultural lines basically can play more than $90 \%$ series County scenic spots in Henan Province, the township level scenic spots around $70 \%$, can integrate the local dispersion of cultural tourism resources, cultural heritage protection, realize win-win economic development, ecological protection. The planning and construction of waterfront greenway has low investment and good effect, short period, quick.

\section{Acknowledgement}

This work was financially supported by the Fund Project Name: 2012 the Ministry of education of Humanities and social sciences research youth fund project "in the construction of new countryside vernacular landscape resources protection strategy research"

Approval of the project: 12YJC760116

\section{References}

[1] Rowling.LAB. Schwartz "green channel. Programming. Design. Development of the" [M]. Beijing: China Building Industry Press, 2009

[2] Rob.H.G. not "ecological network design" [M]. Beijing: Chinese Architecture Industry Press, 2011

[3] Yu Kongjian "back to the land" [M]. Beijing: the Joint Publishing House, 2009

[4] Chen Wei "landscape of new countryside" [M]. Beijing: China Electric Power Press, 2008 